\title{
Patrimônio cultural e processos educativos: uma conversa com Elizabete Tamanini
}

Entrevistada

Entrevistadores

\section{Elizabete Tamanini}

Professora da Universidade da Região de Joinville. Atualmente dedica-se ao pós-doutorado na UNICAMP.

E-mail: btamanini2@gmail.com

Gabriela Berthou de Almeida - Mestranda em História pela Unicamp. E-mail: berthoudealmeida.gabriela@gmail.com

Rúbia Caroline Sousa de Moraes - Graduanda em História pela Unicamp. Email: rubi_carol@yahoo.com.br

Victor S. Menezes - Graduando em História pela Unicamp.

E-mail: henrique.menezes92@gmail.com

R E S U M O

Na presente entrevista o leitor encontrará discussões sobre Patrimônio cultural, bem como acerca dos processos educativos realizados em museus ou em parceria com os mesmos. O texto aborda também a trajetória e os projetos desenvolvidos por Elizabete Tamanini.

Palavras chave: Educação; Museus; Patrimônio Cultural.

\section{N T R O D U Ç Ã O}

Elizabete Tamanini é doutora em Educação pela Unicamp, com enfoque nas áreas de Sociedade e Cultura. Atua há mais de 25 anos em programas de educação não formal em museus e espaços culturais. Atuou como gerente de Patrimônio cultural na Fundação Cultural de Joinville/SC de 2009 a 2011, onde estabeleceu como prioridade a criação de políticas públicas para a cultura e a educação patrimonial. Possuí experiência e pesquisas nas áreas de educação/ formação, educação popular, educação e direitos humanos e educação e Patrimônio Cultural, com foco em processos não formais. Implantou o programa de educação do Museu Arqueológico de Joinville, recebendo por esta ação o prêmio Rodrigo de Mello Franco do Ministério da Cultura. Atualmente é professora da Universidade da Região de Joinville (UNIVILLE) e dedica-se ao pós-doutorado na Unicamp.

$\mathrm{Na}$ entrevista que se segue, Tamanini se posiciona acerca das possibilidades de atuação das instituições vinculadas ao Patrimônio cultural, sobretudo os museus, nos processos educativos. Além disso, a entrevistada expõe sua opinião sobre as perspectivas atuais para os projetos relacionados à educação, que envolvem Patrimônio, cultura material e Arqueologia. 
Entrevistadores: Para começar, gostaríamos que a senhora falasse um pouco sobre sua trajetória enquanto educadora e pesquisadora. Quais foram os caminhos que te levaram a trabalhar e elaborar projetos sobre Arqueologia, Patrimônio e Cultura material?

\section{Elizabete Tamanini:}

A minha inserção nas questões do Patrimônio Cultural e na Arqueologia Pública com centralidade na Educação nasceu na década de 1980, quando iniciei um estágio no Museu Arqueológico de Sambaqui de Joinville/MASJ. Neste momento eu também atuava como professora da Rede Pública de Ensino, no ensino fundamental. A partir das atividades desenvolvidas no ensino formal e no atendimento educativo do MASJ, comecei a observar as relações estabelecidas entre Escola e o Museu. Aos poucos fui percebendo quanto o MASJ necessitava repensar os seus processos de atendimento aos diferentes públicos e o quanto as escolas deveriam ser preparadas para irem a uma instituição como esta e tirar dela temas significativos para o processo de ensino-aprendizagem. Nesta fase de iniciação profissional eu não tinha argumentos conceituais da Museologia ou da Arqueologia Pública para construir um repertório pedagógico. As reflexões sobre estas temáticas no Brasil ainda eram incipientes e pouco divulgadas. Desse modo, passei a estudar e pesquisar possibilidades de unir as teorias de ensino-aprendizagem da Educação às práticas educativas no MASJ. A partir de então, fui me envolvendo de tal forma no atendimento educativo e passei a elaborar projetos educativos que gerassem reflexões acerca das exposições do museu e a estudar processos de formação dos professores. De 1989 em diante, me aprofundei no estudo dessas temáticas. Ingressei no Mestrado em Educação na Unicamp para estudar justamente a problemática da educação em museus. Desta experiência acadêmica pude aprofundar meus conhecimentos acerca da história e função social dos museus. Desta imersão conceitual surgiram os conceitos de criação e sistematização de um Programa Educativo no MASJ, cujas temáticas presentes eram: a formação de professores, com um projeto de atendimento integrado, que priorizava temáticas trabalhadas na matriz curricular do ensino fundamental. Fiz um levantamento do público visitante mais significativo e estratégico do Museu desde a sua abertura em 1973. Observei que grupos que estavam no terceiro, quinto e sétimo anos do ensino fundamental eram os que visitavam com frequência o MASJ. A partir daí, deu-se a sistematização das temáticas em projetos de atendimento educativo voltados ao ensino formal. Passamos a problematizar as complexidades presentes nas temáticas das exposições do MASJ, vinculando tais questões as matrizes curriculares. O trabalho passava pela compreensão do que era a História do Município de Joinville a partir da cultura material, observando os processos diversos da ocupação do território por diferentes povos, a começar pelos sambaquianos, até as questões da História do Brasil. Assim, questões da história regional passam a configurar as atividades no campo da escola. Para este caso vale uma observação: havia neste período uma lacuna bastante acentuada em relação à produção de estudos regionais e com um agravante nas temáticas de Arqueologia Pré-colonial. Neste sentido, estas intervenções conceituais do museu vieram corroborar para a implantação de novas abordagens teóricas sobre a ocupação territorial na região do litoral norte de Santa Catarina. Com base nestas diversas atividades e experiências pedagógicas ao longo do tempo o MASJ foi estruturando ações educativas que transcenderam o espaço físico e institucional comum. Assim criaram-se projetos educativos em comunidades, escolas, etc; ora aprimorando estas atividades em sítios arqueológicos, ora organizando exposições e cursos de formação de professores.

Então, todo o trabalho, toda a minha construção teórica e metodológica dentro do patrimônio cultural, da cultura material e da Arqueologia Pública vincula-se, sobretudo à educação como processo que dialoga com diferentes áreas do conhecimento e que seu 
objetivo final é a compreensão dos processos sociais e a emancipação do ser humano.

\section{Entrevistadores: $\mathbf{O}$ que você entende por cultura material escolar?}

\section{Elizabete Tamanini:}

Cultura material escolar é para mim o conjunto de fontes documentais, que envolve a história de criação da escola enquanto instituição, toda sua organização e estrutura. Inserido nessa perspectiva, o território onde a instituição foi construída, o prédio; a história das aulas, dos cursos, do processo de formação; os registros como matrículas, boletins, diários, livros, bem como o conjunto de artefatos que reúnem os lápis, as carteiras, os quadros, a lousa. Também vale destacar a dimensão da cultura imaterial presente na organização escolar. Desde a organização das aulas, dos recreios e a relação que é construída entre a escola e a comunidade e o sentido dessa escola para aquela comunidade, para os professores e para o Estado ou ente representado.

A Escola para a sociedade de um modo geral, é um lugar de referência, sendo um dos primeiros núcleos de constituição de identidades. É a partir dela que o ser humano começa a ter ideia de sociedade, de organização, de amor, de generosidade, de afeto, de partilha, de coletividade e de individualidade. Assim, ela é um espaço que pode nos levar a uma série de informações e relações com o mundo. Neste lugar há um processo de planejar e organizar o conhecimento, constituído secularmente para ser reproduzido ou construído novamente no processo de ensino-aprendizagem. A escola constitui-se em um relevante patrimônio de referência das memórias sociais, sejam aquelas reproduzidas secularmente, ou ainda estas que a cada instante e a cada momento são construídas e ressignificadas pelo cotidiano escolar.

\section{Entrevistadores: Você pode nos falar um pouco sobre a suas atividades envolvendo educação patrimonial ou Arqueologia Pública, não sabemos como você prefere denominar esse tipo de atividade.}

Elizabete Tamanini:

Eu atuo com Educação e Patrimônio, educação em Museus, Educação Comunitária, Educação Patrimonial e Educação não formal há mais de vinte anos. Atualmente eu não estou inserida em um museu propriamente, mas estou atuando nas discussões de cultura material e educação em interface com o patrimônio público. Em relação à Arqueologia Pública, sejam as ações em contextos pré-colonial ou em outras áreas de intervenção, o uso estratégico e sua aplicação é de extrema relevância para a compreensão dos processos sócio-cultuais especialmente para o mundo contemporâneo. Temos vivenciado no Brasil nestas últimas duas décadas ações significativas onde a Arqueologia deixa de ser uma mera prática de escavação de sítios e elaboração de relatórios técnicos. Há, sobretudo, experiências neste campo cujo objetivo tem sido contribuir para a compreensão da vida e do saber fazer das sociedades. A cultura material é compreendida como tema gerador de coisas/objetos bem mais complexos da existência humana. O desafio posto é intervir em realidades e histórias, tendo em vista, os limites presentes na construção do conhecimento a partir de tais artefatos. Ademais há que se considerar nesta árdua tarefa a responsabilidade de se corroborar com a elaboração de narrativas permanentes sobre povos e culturas. Tema já explorado em críticas e estudos desta área especialmente tratando-se do legado histórico brasileiro.

A Educação Patrimonial vem para as minhas discussões como eixo temático, e não como uma metodologia. Eu situo a Educação Patrimonial enquanto proposta de tematização do Patrimônio Cultural a partir da década de oitenta no Brasil. Minha 
concepção teórico-metodológica vem da Educação Popular. A experiência com os Movimentos Socais na década de oitenta me inspirou a refletir para além dos espaços formais de Educação. Assim, fui juntando as reflexões sobre o processo de ensino e aprendizagem dentro de perspectivas sócio-históricas e analisando que os espaços não formais como museus, centros culturais e outros, educam com intencionalidade. Ao caminhar neste campo do Ensino Formal e Não Formal busquei referências nas atividades desenvolvidas em eco-museus, em experiências comunitárias e em museus que ousavam refletir a sua relação discursiva com os diferentes públicos atendidos. Por influência da minha experiência educativa já vivida, eu via a Educação Patrimonial, como uma prática educativa ainda conservadora. Observava que as ações e experiências de inclusão, de educação popular organizada por muitos movimentos populares passavam ao largo das instituições culturais. E observei em meus estudos que grande parte dos museus estiveram ausentes e se furtaram em contribuir com projetos, ações envolvendo as comunidades, os diferentes grupos sociais no debate de sua cultura material, de sua memória e de seu pertencimento. Algo bastante triste, porque a síntese do trabalho destas instituições e o significado de sua existência são estas temáticas acima colocadas.

Vale ressaltar que em determinados momentos, por ausência de uma concepção teórico-metodológica para se pensar o processo de ensino-aprendizagem nas instituições museológicas, adotou-se posturas e teorias pedagógicas do ensino formal. Em muitos museus foram criados departamentos escolares, não diferenciando conteúdo curricular formal da experiência acadêmica não formal nestes espaços. A nossa discussão posta nestes últimos dez anos vem alimentada pelo trabalho realizado no campo da Educação Não Formal. E é dentro desta categoria, que a educação em museu, ou em espaços culturais, espaços de memória, se estrutura e compõe uma opção na defesa teóricometodológica de compreender que necessitamos abrir as portas destas instituições para as práticas educativas comunitárias. E também de assumirmos do ponto de vista estratégico que as instituições culturais e em especial os museus são responsáveis, e que esta categoria necessita ser visitada e revisitada em consonância com o processo de ensino aprendizagem e em ação constante de avaliação dos efeitos produzidos por este dialogo.

\section{Entrevistadores: Agora direcionando um pouco para o ensino regular: você acredita que esta modalidade de ensino envolvendo patrimônio cultural deve estar inserida no ensino regular? Você tem algum projeto nesse sentido?}

\section{Elizabete Tamanini:}

A formação que ajudamos a construir em museus e espaços não formais, espaços de memória, centros culturais, enfim com um ensino voltado para problematizar a cultura como elemento fundante, vem ao encontro de todas as pedagogias críticas ou todas as práticas escolares protagonistas. Isso porque partimos da seguinte ideia: nós temos a escola, instituição cuja responsabilidade consiste em trabalhar com o conhecimento construído secularmente, para isso, cria-se as matrizes curriculares e planos políticos pedagógicos. A Escola seleciona os conhecimentos, atribui valoração e significado nesse contexto de matriz curricular, que é uma escolha conceitual teórica e estratégica. Considero que a cultura material e o patrimônio cultural presentes em espaços musealizados, ou com esta intencionalidade, são temas inerentes às matrizes curriculares. Quando se discute moradia, território, alimentação, tecnologias com jovens em distintas faixas etárias, percebe-se que há perspectivas e entendimentos diversos, e a partir disso, realidades sociais distintas. Diante disso, o compartilhamento de atividades com lugares que exploram para além das atividades que as escolas e museus promovem, 
podem apresentar outras perspectivas. Isso porque temos outras instituições dialogando, reforçando, realimentando ou até provocando os estudantes a pensarem coisas que vem contradizer o que a escola produz. Deve ser esse então, o papel da construção do conhecimento, do saber.

O problema que eu identifico é que nós da área de museus, de educação, nos afastamos dessa responsabilidade de intervir com mais força e compromisso social com as escolas. Há uma imagem dos museus que professores de escolas e alunos têm. Há imagens que educadores e profissionais de museus têm em relação às escolas, aos alunos e professores. É a partir dessas imagens, com todas as contradições que se tem sobre um e sobre o outro, que necessitamos construir um diálogo possível.

\section{Entrevistadores: De que maneira essas comunidades, estando elas inseridas ou não no ambiente escolar podem participar do processo de reconhecimento patrimônio cultural enquanto tal?}

\section{Elizabete Tamanini:}

Há muito vem se falando da possibilidade de envolver o ensino formal nas atividades desenvolvidas pelos museus. A matriz curricular de uma escola reflete escolhas conceituais históricas, envolve decisão sobre este ou aquele conteúdo. A cultura material presente nos museus também é fruto deste processo de escolha e decisão. Necessitamos neste momento dialogar mais. Os estudos nestas áreas vêm apresentando que já caminhamos com experiências que alcançaram êxito nesta perspectiva. Ressalto também a partir de experiências vivenciadas, ou seja, de uma práxis realizada em muitos museus e escolas. Tendo como base este acúmulo vejo que se os museus tivessem capacidade estrutural financeira e profissional para responder as diferentes provocações contemporâneas, eles certamente estariam contribuindo muito mais com as experiências comunitárias. Estariam preparados cientificamente para promover a formação de opinião, com mentalidades críticas e com decisões sobre patrimônio, conservação e preservação de forma mais participativa. Ainda hoje os museus têm problemas de infraestrutura e permanece enraizado o pensamento dos museus enquanto lugares que cuidam de um passado, de depósitos de objetos, ou como lugares que tornam público curiosidades exóticas. Ainda não conseguimos criar na população de um modo geral a defesa dessa instituição como algo tão importante como uma escola ou um posto de saúde. Há atualmente um movimento para que diversas memórias, diversos patrimônios a partir dessas experiências coletivas possam ser compartilhados, possam ser visibilizados. Neste aspecto a importância da/na formação escolar em parceria com os museus é fundamental para a construção de novas posturas diante da complexa tarefa de educar.

\section{Entrevistadores: Você pode nos falar sobre a sua experiência no Museu do Sambaqui de Joinville?}

Elizabete Tamanini:

O trabalho de educação desenvolvido no Museu Arqueológico de Sambaqui de Joinville foi uma linda experiência. Aprendi a educar para além dos muros do museu e da escola. Me comprometi profundamente com as práticas educativas e trago comigo o compromisso de educar com amorosidade compreendendo o significado deste desafio posto pelo educador Paulo Freire. Atuei como estagiária, depois como educadora contribuindo com projetos educativos para professores e públicos escolares diversos, com reflexões, artigos e pesquisas afins. O que eu poderia materializar dessa longa experiência é a possibilidade de pensar, refletir e produzir projetos e práticas educativas, que levem em consideração a diversidade e complexidade de diferentes públicos que 
visitam este lugar, desde a criança da educação infantil, ensino fundamental, estudantes de graduação de diversas áreas de conhecimento, assim como pesquisadores de mestrado e doutorado. O que tem de significativo neste processo é a leitura sobre a necessidade da profissionalização, de uma documentação das experiências nesse campo educativo e de um compromisso institucional com a formação continuada dos seus diferentes públicos. Vale sobremaneira um olhar cuidadoso para a escola e para as políticas públicas de formação de professores.

Neste campo, é premente a interdisciplinaridade e a construção de compromisso interinstitucional com Universidades e Centros de Pesquisa compartilhando práticas, saberes e pesquisas. Como se sabe o conhecimento é datado, pactuado e só é validado quando compartilhado socialmente. Porém, para além deste movimento institucional, há uma atuação da sociedade e dos sujeitos de forma permanente, ativa, dinâmica. Então, mesmo que estes patrimônios museais sagrados ou não, sejam decretados como referências, como patrimônios culturais ou sociais, o exercício permanente a ser feito é uma constante reflexão sobre o seu significado no presente e no passado.

\section{Entrevistadores: Agora, para finalizar: em sua opinião, quais são as perspectivas para os projetos envolvendo Patrimônio, cultura material e Arqueologia, relacionados à educação no Brasil?}

\section{Elizabete Tamanini:}

Eu sou professora há quase trinta anos e como apaixonada pela profissão tenho comigo uma perspectiva e uma história voltada ao desejo e à mobilização das pessoas para o saber. Então, olhando esses trinta anos de trabalho, eu sinto que avançamos em relação à legislação, às práticas de proteção, às ações de formação na educação e também na perspectiva das responsabilidades interdisciplinares. Venho construindo experiências pedagógicas com escolas e museus e cada vez mais as comunidades, as instituições, os grupos, as pessoas vêm desejando refletir sobre a sua história, sobre o seu patrimônio, sobre as suas identidades, desejam ser sujeitos, indivíduos, inseridos em uma coletividade. Também neste sentido avaliamos que há uma geração muito nova fazendo parte de estudos universitários, estudantes que têm desejos de mudanças, desejos de contribuir com a criação de novas experiências acadêmicas e sociais. Tendo essas referências como parte da vida dos seres humanos, como parte das experiências humanas em construção, coisas em movimento, como espelhos para a nossa existência. 